\title{
Value Tools in Managed Care Decision Making: Current Hurdles and Future Opportunities
}

\author{
Jeremy Schafer, PharmD, MBA; Dominic Galante, MD; and Jason Shafrin, PhD
}

\begin{abstract}
BACKGROUND: Organizations such as the National Comprehensive Cancer Network, American Society of Clinical Oncology, Institute for Clinical and Economic Review, and Memorial Sloan Kettering have created distinct tools to help different stakeholders assess the value of oncology treatments. However, the oncology value tools were not necessarily created for payers, and it is unclear whether payers are using these tools as part of their drug management process.
\end{abstract}

OBJECTIVE: To understand what value tools payers are using in oncology management and what benefits and shortcomings the tools may have from the payer perspective.

METHODS: A survey targeting drug coverage decision makers at health plans was conducted in August 2016. Respondents attesting to using 2 or more value tools in drug management were eligible for an additional in-depth interview to understand the respondents' perceived benefits and shortcomings of current value tools. Respondents also were asked to describe desired attributes of a hypothetical payer-centric value tool.

RESULTS: A total of 28 respondents representing approximately 160 million commercially insured medical lives completed the survey. Twenty respondents $(71 \%)$ reported using at least 1 value tool in their drug management process. Twelve respondents ( $43 \%$ ) used at least 2 tools, and 4 respondents $(14 \%)$ used at least 3 tools. A total of 6 respondents were selected for in-depth interviews. Interviewees praised value tools for advancing the discussion on drug value and incorporating clinical evidence. However, interviewees felt available value tools varied on providing firm recommendations and relevant price benchmarks. Respondents most commonly recommended the following attributes of a proposed payer-centric value framework: taking a firm position on product value; product comparisons in lieu of comparative clinical trials; web-based tool access; and tool updates at least quarterly. Interview respondents also expressed some support for allowing manipulation of inputs and inclusion of quality-of-life and patientreported outcome data.

CONCLUSIONS: Although nearly half of payers surveyed use 2 or more value tools in the drug management process, payers identified a number of areas where the tools could be revised to increase their utility to payers.

J Manag Care Spec Pharm. 2017;23(6-a):S21-S27

Copyright $\odot 2017$, Academy of Managed Care Pharmacy. All rights reserved.

\section{What is already known about this subject}

The rising costs of oncology medications have influenced new methods of payer management and the creation of oncology value frameworks.

Existing oncology value frameworks, including the American Society of Clinical Oncology Value Framework, National Comprehensive Cancer Network Evidence Blocks, Institute for Clinical and Economic Review analyses, and Memorial Sloan Kettering's DrugAbacus, have unique benefits and drawbacks for use in payer oncology management.

It is unclear, however, to what extent these tools are currently being used by payers and how they could be improved to provide additional utility to payers.

\section{What this study adds}

Forty-three percent of payers surveyed use 2 or more value tools in the drug management process.

Payers identified a number of areas where the tools could be revised to increase their utility to payers, including taking a firm position on product value; product comparisons in lieu of comparative clinical trials; web-based tool access; and tool updates at least quarterly, allowing manipulation of inputs and inclusion of quality-of-life and patient-reported outcome data.

B etween 2000 and 2014, the price of patented cancer medications increased 5- to 10 -fold, with 12 of the 13 cancer drugs approved in 2012 having an annual cost exceeding $\$ 100,000 .^{1}$ These increases impact payers and patients in both commercial and government-funded (e.g., Medicare, Medicaid) markets. ${ }^{2}$ In response, payers are trying a variety of tactics to rein in costs. Pathway programs have been used by payers to simplify the prior authorization process and identify inappropriate use. $^{3}$ Capitated arrangements and oncology accountable care organizations (ACOs) attempt to shift risk and encourage the use of lower-cost therapies. ${ }^{4,5}$ CVS Caremark added oncology medications for prostate cancer and chronic myelogenous leukemia to the CVS 2017 exclusion list in an effort to curb costs. ${ }^{6}$

Another tactic payers could use is to rely on value frameworks to help inform pricing or coverage decisions. These frameworks vary by design but all attempt a similar goal: to quantify and compare the overall value and cost of an oncology drug. Evaluating cost-effectiveness in oncology is not a 
new concept in many parts of the world. The National Institute of Clinical Excellence (NICE) in the United Kingdom calculates the quality-adjusted life-year (QALY) gained for drugs approved in the United Kingdom and determines coverage by the National Health Service. ${ }^{7}$ NICE has routinely rejected oncology agents that had costs per QALY's estimates that exceeded its threshold. ${ }^{8}$

The United States lacks a government entity such as NICE, but independent organizations have begun similar evaluations. The Institute for Clinical and Economic Review (ICER), a nonprofit organization that evaluates evidence on the value of medical tests, treatments, and delivery system innovations, has been in the news for reviews of drugs for multiple myeloma and lung cancer., ${ }^{9,10}$ Memorial Sloan Kettering's DrugAbacus allows users to adjust different inputs and calculate a recommended price for comparison to a drug's list price. ${ }^{11}$ Value frameworks may not create grounds for noncoverage on a national level but do provide, for the first time, a view into the value of a therapy and, with some frameworks, a therapy's cost-effectiveness.

For managed care professionals, the challenge is deciding how to integrate existing value frameworks into the drug management process or determining if such tools should be used at all. One of the complications is that some value frameworks may not be intended for coverage decisions. The American Society of Clinical Oncology (ASCO) Value Framework was explicit in stating the tool was "not meant to be a policy tool."12 Other complications such as the frequency of updates and variation in drugs reviewed makes frameworks use by payers difficult. Despite the complications, there is evidence that managed care professionals responsible for managing pharmacy budgets are forging ahead with using value frameworks in drug management anyway. ${ }^{13}$

Information is limited on the shortcomings of oncology value frameworks for managed care pharmacists and medical directors. Recommendations are needed from managed care professionals currently using value frameworks on how to make valuation more relevant to a payer. Such recommendations could lead to the evolution or even creation of value frameworks designed for payer drug management.

The objective of our research was to determine the prevalence of value framework use in managed care decision making, such as formulary and utilization management. Additionally, we sought to better understand the benefits and shortcomings of these value frameworks from the point of view of managed care professionals.

\section{Methods}

$\overline{\text { We conducted a convenience sample from a survey database }}$ consisting of nearly 2,000 managed care professionals, including doctors, pharmacists, and individuals in drug management roles at health plans and pharmacy benefit management companies (PBMs). The database is a proprietary database developed and owned by Precision for Value. The database includes 1,047 individuals who were employed at commercial health plans, 358 at PBMs, 349 at Medicaid plans, and 91 at Medicare plans. Individuals in the database are contacted annually to verify any changes to their employer, title, or responsibilities.

For plans with multiple lines of business (commercial and government), categorization is based on the segment of business constituting the most covered lives. Organizations included in the database represent more than $90 \%$ of covered lives in the United States. Inclusion criteria for potential study participants included employment at a health plan; a title of pharmacy or medical director; involvement in drug formulary or drug coverage policy decision making; coverage of commercial, managed Medicaid, and/or Medicare lives; and a covered lives count of at least 50,000 for the organization. The minimum of 50,000 covered lives was used to ensure that the survey responses represented a relatively large number of insured lives. Participants were categorized as either "pharmacy" or "medical" depending on their job title. Individuals with a history of responding to prior surveys were selected for the sample.

The online survey was conducted using Qualtrics survey software. The survey consisted of the following question: Which oncology value tool(s) does your organization use to inform its drug management? Respondents could select 1 or more of the following options: ASCO Value Framework, Memorial Sloan Kettering's DrugAbacus, ICER analyses, National Comprehensive Cancer Network (NCCN) Evidence Blocks, Other (free text input), and None. The survey was launched on August 19, 2016, and closed on August 24, 2016.

Respondents stating that they used 2 or more value frameworks to influence oncology management were eligible for a follow-up in-depth interview conducted via phone. The indepth interview took approximately 30 minutes. The interview guide focused on understanding what the pros and cons of each value tool were for use in payer drug management and what changes the respondent would recommend to enhance an existing tool for payer use (Appendix). Interview questions were developed by the authors and were based in part on prior research on how payers are using value frameworks in managed care. ${ }^{13}$ Furthermore, interview subjects were questioned on what attributes and functions should be included in a hypothetical payer-centric value tool designed for the purpose of informing payer drug management.

The survey and research interviews were conducted as a component of a marketing research project. The interviewer was blinded to the identity of the interviewees. All survey respondents and interviewees received remuneration for their input. Interviewee responses were provided as raw data to show individual insights on how value frameworks could be optimized for payers. Responses were weighted equally, regardless of the number of lives covered by the organization that each individual represented. 


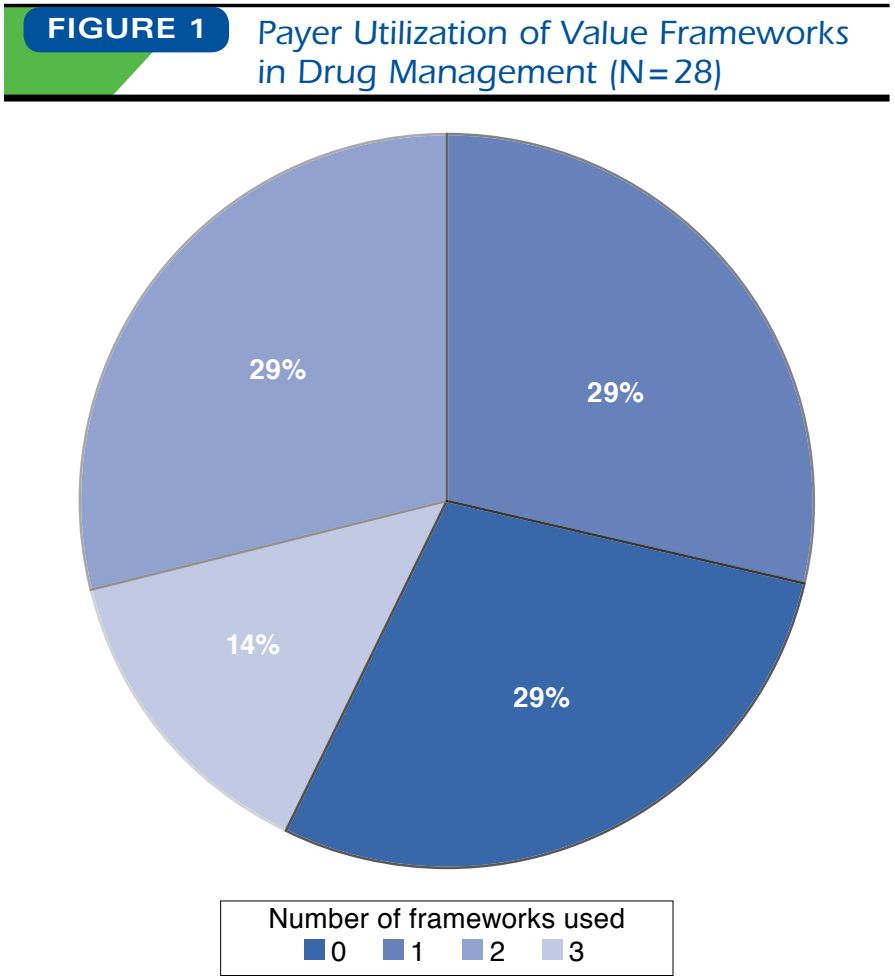

Note: The total is greater than $100 \%$ because of rounding.

\section{Results}

A total of 269 medical directors and 65 pharmacy directors met the inclusion criteria. Using a convenience sample approach as noted in the methods, we sent the survey to 54 individuals, of which 28 responded (a response rate of 52\%). Respondents represented 27 unique organizations. Nineteen organizations had covered lives in commercial, Medicare (Medicare Advantage Part D and Part D prescription drug plans), and managed Medicaid lines of business. Commercial/Medicare and commercial/managed Medicaid were the business mixes of 3 and 2 responding organizations, respectively. One health plan had managed Medicaid/Medicare business and 2 were managed Medicaid only.

A majority of respondents (17 of 28) had the title of medical director, and the rest of the sample had the title of pharmacy director (11 of 28). Interviewees represented large, medium, and small plans covering 160 million lives. Respondents from 5 health plans covered more than 10 million insured lives; respondents from 10 health plans covered between 1 million and 10 million insured lives; and 12 health plans covered fewer than 1 million insured lives.

Twenty respondents (71\%) attested to using at least 1 oncology value framework to inform drug management (Figure 1). The NCCN Evidence Blocks was the most used value framework, with 20 respondents (71\%) using the tool. The ASCO

\begin{tabular}{l|l|l}
\hline \multicolumn{1}{c}{ TABLE 1 } & \multicolumn{1}{c}{$\begin{array}{l}\text { Positive and Negative Attributes of } \\
\text { Value Frameworks for Payers (N=6) }\end{array}$} \\
\hline Framework & \multicolumn{1}{|c}{ Positive Attributes } & \multicolumn{1}{c}{ Negative Attributes } \\
\hline $\begin{array}{l}\text { ASCO Value } \\
\text { Framework }\end{array}$ & $\begin{array}{l}\text { Evidence-based (1), allows } \\
\text { comparison to older prod- } \\
\text { ucts to calculate benefit of } \\
\text { new therapies (1) }\end{array}$ & $\begin{array}{l}\text { No comparisons outside } \\
\text { direct head-to-head trials } \\
\text { (1), does not make firm rec- } \\
\text { ommendations on value (2) }\end{array}$ \\
\hline $\begin{array}{l}\text { NCCN } \\
\text { Evidence }\end{array}$ & $\begin{array}{l}\text { Easy to use (2), regularly } \\
\text { updated (3), aligns with } \\
\text { Blocks }\end{array}$ & $\begin{array}{l}\text { Affordability not quantified } \\
\text { (3), reliance on expert opin- } \\
\text { ion (2) }\end{array}$ \\
\hline ICER analyses & $\begin{array}{l}\text { Compares products on } \\
\text { calculated value price (2), } \\
\text { scientific (1) }\end{array}$ & $\begin{array}{l}\text { Can be difficult to navigate } \\
\text { (1), not updated (1), focus on } \\
\text { new drugs (1) }\end{array}$ \\
\hline DrugAbacus & Unbiased (1) & $\begin{array}{l}\text { Not necessarily intended for } \\
\text { payer use (1) }\end{array}$ \\
\hline
\end{tabular}

Note: Numbers in parentheses refer to number of respondents citing answer in interview.

Value Framework and ICER analyses were used by 8 (29\%) and 7 (25\%) respondents, respectively. DrugAbacus was used by a single respondent (4\%), and no respondents selected "other."

A total of 6 respondents using 2 or more value tools agreed to a follow-up in-depth interview, for a participation rate of $50 \%$. The 6 respondents represented 6 unique organizations. Three interviewees used 3 value tools and 3 interviewees used 2 value tools in drug management. All 6 interview subjects used the NCCN Evidence Blocks in their organization's drug management. Additionally, 5 individuals used ICER analyses, 3 used the ASCO Value Framework, and 1 used DrugAbacus.

Interviewees provided recommendations on what would make each value tool more useful to payers (Table 1). Payer respondents felt the inclusion of a quantified value was needed in the NCCN Evidence Blocks versus the existing graphical representation. Inclusion of medical cost offset of drug therapy would also enhance the NCCN Evidence Blocks for payers. The ICER analyses could be improved by creating more concise payer value summaries to minimize time spent sifting through entire reports. Interviewees recommended that the ASCO Value Framework expand into comparisons of products not directly compared in a head-to-head trial, as such comparisons are frequently required of payers.

Interviewees felt a payer-centric tool should be based on high-quality clinical evidence to support decisions, with a smaller role for provider input and expert opinion (Figure 2). Despite reliance on clinical data, product comparisons outside head-to-head trials were seen as crucial to support decisions on preferred products. Respondents recommended that incremental QALYs gained relative to the treatment status quo be calculated as well as how a therapy changes life expectancy and the associated cost. Payers acknowledged the difficulties in standardization of patient-reported outcomes and quality of life but saw both as useful for the tool, given the terminal nature 


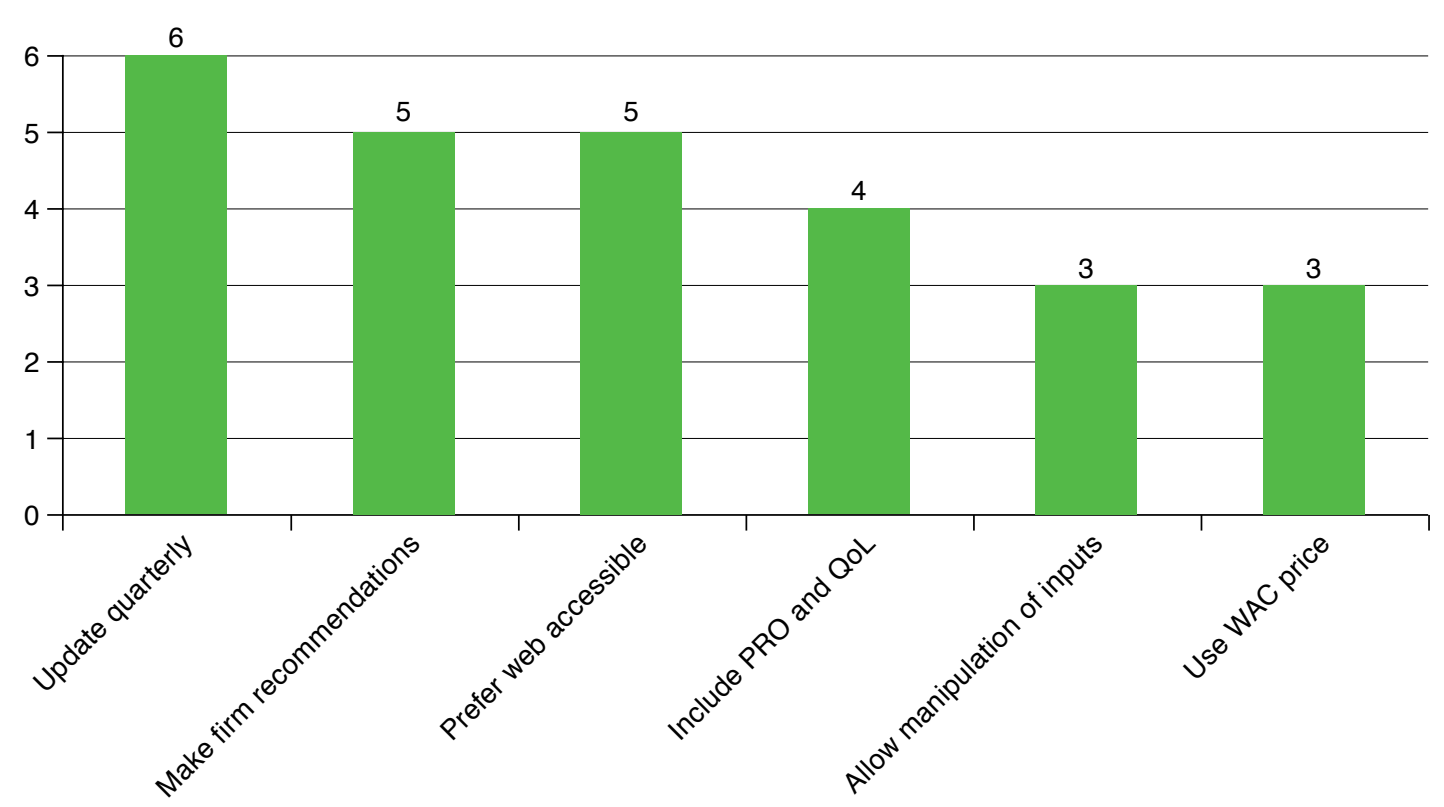

$P R O=$ patient-reported outcome; $Q \mathrm{oL}=$ quality of life; WAC = wholesale acquisition cost.

of many cancers. A rank order output of efficacy, safety, quality of evidence, and financial impact, in quantified dollars, was recommended to mirror a payer review process. Payers wanted the tool to take a firm stance on recommendations that would allow dialogue with providers on coverage by leveraging a wellreferenced and credible information source.

\section{Discussion}

Our study found that a majority of respondents (71\%) used at least 1 value framework when evaluating oncology treatments. Interviewees conceded that available value frameworks had limitations in drug management. These limitations, however, did not stop the interviewees from leveraging the value frameworks to make coverage decisions. The movement toward value-based care will likely expand the use of value frameworks by payers. More experience in value frameworks may prompt payers to use the tools more strategically in determining drug coverage and preferred products. Widespread use of value frameworks may result in more value considerations in drug evaluation and place a greater emphasis on how cost and clinical data are related versus the current approach of reviewing these metrics separately.

A prior survey found that $27 \%$ of payer respondents used an oncology value framework in their formulary or drug management process and a further $41 \%$ planned to do so in the future. ${ }^{13}$ The higher use of value tools in our current survey may be due to the targeting of health plan medical and pharmacy directors versus PBM, as was done in the prior survey. Alternatively, it could be the case that value frameworks are gaining a larger foothold for payers, as this study was conducted approximately 8 months after the first one. In fact, a recent survey of users of the Academy of Managed Care Pharmacy eDossier System found that $75 \%$ used ICER reports to inform their own analyses, with 33\% of these individuals using ICER reports in developing coverage policy. ${ }^{14}$

Although this study examined value and value frameworks from a payer perspective, value frameworks are likely to be used increasingly by health care providers as well. Three of the value frameworks in our survey were developed by provider organizations or health systems. Providers' reimbursement increasingly depends on the quality and cost of care they deliver to patients. For instance, Medicare's Quality Payment Program, Shared Savings Program, and Oncology Care Model all follow this value-based approach to care. ${ }^{15}$ ACOs are the most widely known alternative payment models instituted by the Affordable Care Act and expanded by the Medicare Access and CHIP Reauthorization Act. Private payers' initiatives such as UnitedHealthcare's Value-Based Care program and Anthem's Enhanced Personal Health Care program also increasingly are linking provider reimbursement to value. ${ }^{16,17}$

Although payers, providers, and others are all concerned about "value," how value is measured should be tailored to 
the relevant stakeholder. ${ }^{18}$ For instance, the ASCO Value Framework aims to be a tool to facilitate patient-provider joint decision making rather than to facilitate payer coverage decisions. Further, the Second Panel on Cost Effectiveness in Health and Medicine recommends measuring value and costeffectiveness not only from the payer perspective, but also from the societal perspective. Even though many value frameworks claim to take a societal perspective, these frameworks often omit important value dimensions such as caregiver burden, patient transportation costs, or nonhealth-sector costs. ${ }^{19}$ In short, value frameworks that provide significant utility to payers may not necessarily be useful for other stakeholders such as patients, providers, or policymakers.

\section{Limitations}

This study had a number of key limitations. The analysis involved a panel that participated in market research and thus may not be representative of payers unable or unwilling to partake in market research. The sampling design was a convenience sample, and interview respondents represented only 6 organizations and may not be representative of a broader group of regional and state payers. However, the number of covered lives from the 6 organizations represented was significant.

Similarly, the larger survey included 28 respondents from 27 unique organizations. While these 27 organizations provided coverage for approximately 160 million lives, smaller payers or large payers not responding to the survey may not be represented. The sample included more medical directors than pharmacy directors, which may have skewed the results. Additionally, individuals interested in value frameworks or value in general may have been more or less likely to respond to the survey than those with limited knowledge of these topics.

This research also did not specifically address how value frameworks are used by payers, but this type of research has been done previously. ${ }^{13}$ Finally, lack of further analysis on interviewee responses may not capture the impact of recommendations on total covered lives.

\section{Conclusions}

About 7 in 10 payers surveyed use at least 1 value tool in their drug management process. Respondents identified a number of areas where the tools could be revised to increase their utility to payers, such as taking a firm position on product value; product comparisons in lieu of comparative clinical trials; webbased tool access; and allowing manipulation of inputs, tool updates at least quarterly, and inclusion of quality-of-life and patient-reported outcome data. Improving the utility of a value framework to payers, however, may make the revised tool more or less useful to other stakeholders such as patients, providers, and policymakers.

\section{Authors}

JEREMY SCHAFER, PharmD, MBA, and DOMINIC GALANTE, MD, Precision for Value, Gladstone, New Jersey. JASON SHAFRIN, PhD, Precision Health Economics, Los Angeles, California.

AUTHOR CORRESPONDENCE: Jeremy Schafer, PharmD, MBA, Senior Vice President, Specialty Solutions, Precision for Value, 240 Main St., Gladstone, NJ 07934.

E-mail: Jeremy.schafer@precisionforvalue.com.

\section{DISCLOSURES}

No outside funding or assistance of any kind was used for this research or in manuscript preparation. Schafer and Galante are employed by Precision for Value, a payer ad marketing agency that works exclusively with life science companies. Shafrin is employed by Precision Health Economics, a consulting company to insurance and life science industries.

Shafer, along with Galante and Shafrin, contributed to study design, data collection, and manuscript preparation. The authors contributed equally to data analysis and interpretation and manuscript revision.

\section{REFERENCES}

1. Kantarjian H, Steensma D, Sanjuan JR, et al. High cancer drug prices in the United States: reasons and proposed solutions. J Onc Pract. 2014;10(4):e208-11

2. Dusetzina SB, Keating NL. Mind the gap: why closing the doughnut hole is insufficient for increasing Medicare beneficiary access to oral chemotherapy. J Clin Oncol. 2016;34(4):375-80.

3. Gesme DH, Wiseman M. Strategic use of clinical pathways. J Onc Pract. 2011;7(1):54-56

4. Ho V, Allen TK, Kim U, et al. Measuring the cost implications of the collaborative accountable care initiative in Texas. Am J Manag Care. 2016;22(9):e304-10

5. Newcomer LN, Gould B, Page RD, et al. Changing physician incentives for affordable, quality cancer care: results of an episode payment model. J Onc Pract. 2014;10(5):322-26.

6. CVS Health. 2017 standard formulary list of removals and updates. Available at: http://investors.cvshealth.com/ /media/Files/C/CVSIR-v3/documents/02-aug-2016/2017-standard-formulary-list-of-removals-and-updates.pdf. Accessed April 4, 2017

7. National Institute for Health and Care Excellence. Judging whether public health interventions offer value for money. Available at: https://www.nice org.uk/advice/lgblo/chapter/judging-the-cost-effectiveness-of-public-healthactivities. Accessed April 4, 2017.

8. Hill A. NICE 'no' for Opdivo in kidney cancer. PMLive. Available at: http://www.pmlive.com/pharma_news/nice_no_for_opdivo_in_kidney_cancer_1058451. July 5, 2016. Accessed April 4, 2017.

9. Institute for Clinical and Economic Review. Multiple myeloma: final evidence report and meeting summary. Available at: https://icer-review.org/ material/mm-final-report/. June 9, 2016. Accessed April 4, 2017.

10. Institute for Clinical and Economic Review. Non-small cell lung cancer: evidence report. September 29, 2016. Updated October 7, 2016. Available at: https://icer-review.org/material/nsclc-evidence-report/. Accessed April 4, 2017.

11. Memorial Sloan Kettering Cancer Center. DrugAbacus. Available at: http://www.drugabacus.org/drug-abacus/tool/. Accessed April 4, 2017.

12. Schnipper LE, Davidson NE, Wollins DS, et al. Updating the American Society of Clinical Oncology Value Framework: revisions and reflections in response to comments received. J Clin Oncol. 2016;34(24):2925-34. Available at: http://ascopubs.org/doi/full/10.1200/jco.2016.68.2518. Accessed April 4, 2017. 
13. Schafer J, Rademacher K, Serluco J. The rising use of oncology value tools by payers. J Clin Pathways. 2016;2(6). Available at: http://www. journalofclinicalpathways.com/article/rising-use-oncology-value-tools-payers. Accessed April 4, 2017.

14. Lising A, Rosner A, Gladman J, Drummond M. Payers' use of ICER reports in decision-making. October 2016. Available at: http://nexus2016. amcp.org/bronze-abstract-payers-use-of-icer-reports-in-decision-making/. Accessed April 4, 2017.

15. Centers for Medicare \& Medicaid Services. CMS announces additional opportunities for clinicians to join innovative care approaches under the Quality Payment Program [press release]. October 25, 2016. Available at: https://www.cms.gov/Newsroom/MediaReleaseDatabase/Pressreleases/2016-Press-releases-items/2016-10-25.html. Accessed April 4, 2017.
16. UnitedHealthcare. Care providers and value-based care. Available at: https://www.uhc.com/valuebasedcare/how-value-based-care-benefits-you/ for-care-providers. Accessed April 4, 2017.

17. Anthem. Early results from the enhanced personal health care program: learnings for the movement to value-based payment. March 2016. Available at: http://thinkanthem.com/sites/default/files/EPHC_WhitePaper_ ProviderCollaboration_FINALV2.pdf. Accessed April 4, 2017.

18. Chandra A, Shafrin J, Dhawan R. Utility of cancer value frameworks for patients, payers, and physicians. JAMA. 2016;315(19):2069-70.

19. Sanders GD, Neumann PJ, Basu A, et al. Recommendations for conduct, methodological practices, and reporting of cost-effectiveness analyses: second panel on cost-effectiveness in health and medicine. JAMA. 2016;316(10):1093-1103. 


\section{APPENDIX Discussion Guide for Interview}

1. How long have you been using oncology value tools in your drug management processes?

2. Of the value tools you are using, which one have you found to be the most valuable? Why?

3. Of the value tools you are using, which one have you found least valuable? Why?

4. You stated in a prior survey that you use the American Society of Clinical Oncology (ASCO) framework in your drug management processes. What are the positives and negatives to the ASCO framework in the drug management process for a payer?

a. How would you improve the ASCO framework to make it more useful to payers?

5. (Same question as 4 but for DrugAbacus)

6. (Same question as 4 but for National Comprehensive Cancer Network Evidence Blocks)

7. (Same question as 4 but for Institute for Clinical and Economic Review)

8. If you could design a payer-specific oncology value tool, what attributes or inputs would you include?
a. Allow input manipulation (yes or no)
b. Take "hard" stance (yes or no)
c. How tool is available
d. Frequency of updates
e. Financial input
f. Patient-reported outcome (PRO) or quality-of-life (QoL) input consideration 